Supplement of Atmos. Chem. Phys., 15, 6929-6942, 2015

http://www.atmos-chem-phys.net/15/6929/2015/

doi:10.5194/acp-15-6929-2015-supplement

(C) Author(s) 2015. CC Attribution 3.0 License.

(c) (i)

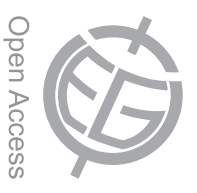

Supplement of

\title{
Estimates of non-traditional secondary organic aerosols from aircraft SVOC and IVOC emissions using CMAQ
}

M. C. Woody et al.

Correspondence to: S. Arunachalam (sarav@email.unc.edu)

The copyright of individual parts of the supplement might differ from the CC-BY 3.0 licence. 


\title{
Supplementary Information for Estimates of Non-traditional Secondary Organic Aerosols from Aircraft SVOC and IVOC Emissions Using CMAQ
}

\author{
Matthew C. Woody, J. Jason West, Shantanu H. Jathar, \\ Allen L. Robinson, and Saravanan Arunachalam
}

\section{Contents}

1 VBS vs. AE6 in CMAQ 1

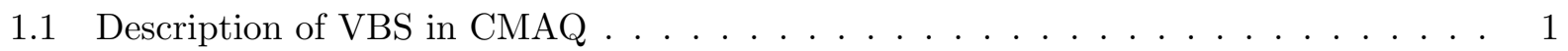

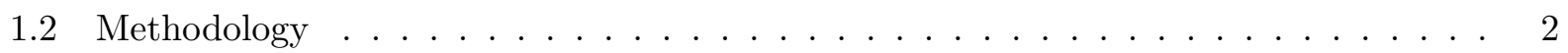

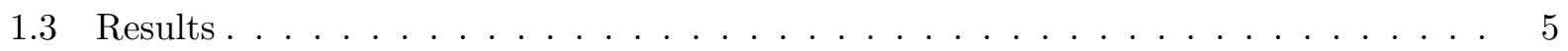

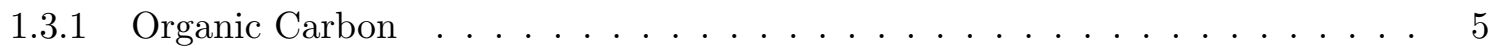

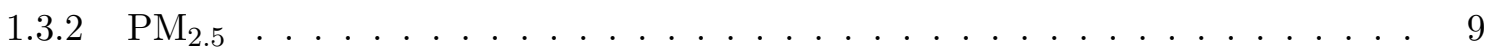

2 Additional Figures and Tables $\quad 10$

\section{$1 \quad$ VBS vs. AE6 in CMAQ}

\subsection{Description of VBS in CMAQ}

VBS in CMAQ, implemented by Koo et al. (2014) for the Carbon Bond 2005 (CB05) chemical mechanism (Yarwood et al., 2005), includes four distinct organic aerosol groups: primary anthropogenic (representing hydrocarbon-like OA), secondary anthropogenic and biogenic (representing oxygenated OA), and primary biogenic (biomass burning). Five volatility bins are used to represent the four semi-volatile groups, with the lowest bin being non-volatile and the other four bins representing particles with $\mathrm{C}^{*}$ values ranging from $10^{0}$ to $10^{3} \mathrm{\mu g} \mathrm{m}^{-3}$. Stoichiometric yields representing semi-volatile products of SOA gas-phase precursors are based on Murphy and Pandis (2009) except for toluene, which is based on Hildebrandt et al. (2009) and are summarized in Table $\mathrm{S} 1$. Formation of SOA from aromatics, isoprene, and monoterpenes precursors include both high and low- $\mathrm{NO}_{x}$ yields. Anthropogenic SOA is aged by reactions with $\mathrm{OH}$ using a rate constant of 2 
$\mathrm{x} 10^{-11} \mathrm{~cm}^{3}$ molecules ${ }^{-1} \mathrm{~s}^{-1}$, with each aging reaction reducing volatility by an order of magnitude and adding approximately $3 \%$ to the SOA mass (Murphy and Pandis, 2009). Biogenic SOA is not aged (Murphy and Pandis, 2009), though the exclusion of biogenic aging reactions may not be a good assumption based on smog chamber data (Donahue et al., 2012). POA is aged by OH with a rate constant of $4 \times 10^{-11} \mathrm{~cm}^{3}$ molecules ${ }^{-1} \mathrm{~s}^{-1}$ (Robinson et al., 2007), lowering volatility by a order of magnitude with $87-90 \%$ of the mass (depending on the volatility of the parent POA oxidized) retained as POA and 7-9\% transfered to SOA (Koo et al., 2014). The conversion of a portion of POA (hydrocarbon-like OA) to SOA (oxidized OA), is based on carbon and oxygen balances (Koo et al., 2014). SVOCs emissions, which partition between the particle and gas phase, replace POA emissions. To account for the loss of particles to the gas phase, particle formation from IVOC emissions are added. The VBS implementation includes two options to internally estimate SVOC and IVOC emissions at runtime based on traditional POA emission inventories, a conservative and a high case both within the uncertainty range of S/IVOC emissions. In the conservative case, the total mass of SVOC emissions are estimated to be equal to traditional POA emissions while IVOC emissions are estimated as 1.5 times POA emissions (Robinson et al., 2007). In the high SVOC and IVOC emission case, SVOC emissions are estimated as 3 times POA emissions while IVOCs are estimated as 4.5 times POA emissions (Shrivastava et al., 2011). Table S2 indicates the fraction of POA mass assigned to each volatility bin of SVOC emissions.

\subsection{Methodology}

In this study, the CMAQ v5.0.1 VBS implementation developed by Koo et al. (2014) was expanded for use with the more explicit SAPRC-07 chemical mechanism (Carter, 2010). Updated and added reactions are listed in Tables S4 and S5 of Section 2. In CMAQ, our VBS implementation for SAPRC-07 includes 150 gas phase species [13 representing SOA precursors - 9 anthropogenic (8 contained in aircraft emissions) and 4 biogenic] and 413 reactions compared to 80 gas phase species (6 representing SOA precursors - 3 anthropogenic and 3 biogenic) and 205 reactions in CB05. SAPRC-07 oxidation products of gas-phase SOA precursors were updated from traditional Odum 2-product (Odum et al., 1996) species to VBS species with yields taken from Murphy and Pandis (2009) and Hildebrandt et al. (2009) and identical to Koo et al. (2014) (Table S1), while the aerosol module remained unchanged from Koo et al. (2014).

Three different scenarios were modeled for January and July, 2002 over a nested 12-km Eastern U.S. domain: 1) CMAQ with the traditional model for organic aerosols (AE6), 2) CMAQ with VBS and conservative estimates of S/IVOC emissions (VBS) and 3) CMAQ with VBS and high estimates of S/IVOC emissions (high S/IVOC VBS). Model inputs are based on those used in Hutzell et al. (2012). Briefly, meteorological inputs were generated using the Pennsylvania State University/NCAR mesoscale (MM5) model (Grell et al., 1994). Emissions were generated using the 
Table S1: CMAQ mass-based VBS yields $\left[\left(\mathrm{g} \mathrm{m}^{-3}\right) /\left(\mathrm{gg} \mathrm{m}^{-3}\right)\right]$ for the CB05 (Koo et al., 2014) and SAPRC-07 (this work) chemical mechanisms.

\begin{tabular}{|c|c|c|c|c|c|c|c|c|}
\hline \multirow[b]{3}{*}{ Model Species } & \multicolumn{8}{|c|}{ CB05 and SAPRC-07 Mechanisms } \\
\hline & \multicolumn{4}{|c|}{ High $\mathrm{NO}_{x}$ Yields } & \multicolumn{4}{|c|}{ Low $\mathrm{NO}_{x}$ Yields } \\
\hline & $10^{0}$ & $10^{1}$ & $10^{2}$ & $10^{3}$ & $10^{0}$ & $10^{1}$ & $10^{2}$ & $10^{3}$ \\
\hline $\mathrm{BENZ}^{\mathrm{a}}$ & 0.0030 & 0.1659 & 0.3000 & 0.4350 & 0.0750 & 0.2250 & 0.3750 & 0.5250 \\
\hline $\mathrm{TOL}^{\mathrm{b}}$ & 0.0110 & 0.2480 & 0.4660 & $0.6940^{\mathrm{d}}$ & 0.0110 & 0.2480 & 0.7250 & $0.4520^{\mathrm{d}}$ \\
\hline$X Y L^{a, c}$ & 0.0015 & 0.1950 & 0.3000 & 0.4350 & 0.0750 & 0.3000 & 0.3750 & 0.5250 \\
\hline $\mathrm{ISOP}^{\mathrm{a}}$ & 0.0000 & 0.0225 & 0.0150 & 0.0000 & 0.0090 & 0.0300 & 0.0150 & 0.0000 \\
\hline TERPa & 0.0120 & 0.1215 & 0.2010 & 0.5070 & 0.1073 & 0.0918 & 0.3587 & 0.6075 \\
\hline \multirow[t]{4}{*}{$\mathrm{SESQ}^{\mathrm{a}}$} & 0.0750 & 0.1500 & 0.7500 & $0.5090^{\mathrm{d}}$ & 0.0750 & 0.1500 & 0.7500 & $0.5090^{\mathrm{d}}$ \\
\hline & \multicolumn{8}{|c|}{ SAPRC-07 Mechanism Only } \\
\hline & \multicolumn{4}{|c|}{ High $\mathrm{NO}_{x}$ Yields } & \multicolumn{4}{|c|}{ Low $\mathrm{NO}_{x}$ Yields } \\
\hline & $10^{0}$ & $10^{1}$ & $10^{2}$ & $10^{3}$ & $10^{0}$ & $10^{1}$ & $10^{2}$ & $10^{3}$ \\
\hline $\mathrm{ARO}^{\mathrm{b}}$ & 0.0110 & 0.2480 & 0.4660 & 0.6940 & 0.0110 & 0.2480 & 0.7250 & 0.4520 \\
\hline $\mathrm{ARO} 2^{\mathrm{a}}$ & 0.0015 & 0.1950 & 0.3000 & 0.4350 & 0.0750 & 0.3000 & 0.3750 & 0.5250 \\
\hline TRIMETH_BENZ124 ${ }^{\mathrm{a}}$ & 0.0015 & 0.1950 & 0.3000 & 0.4350 & 0.0750 & 0.3000 & 0.3750 & 0.5250 \\
\hline ALK5 $5^{\mathrm{a}}$ & 0.0000 & 0.1500 & 0.0000 & 0.0000 & 0.0000 & 0.3000 & 0.0000 & 0.0000 \\
\hline APIN $^{\mathrm{a}}$ & 0.0120 & 0.1215 & 0.2010 & 0.5070 & 0.1073 & 0.0918 & 0.3587 & 0.6075 \\
\hline \multicolumn{9}{|c|}{${ }^{\mathrm{a}}$ Murphy and Pandis (2009) } \\
\hline \multicolumn{9}{|c|}{ b Hildebrandt et al. (2009) } \\
\hline \multicolumn{9}{|c|}{ c SAPRC-07 includes MXYL, OXYL, and PXYL } \\
\hline
\end{tabular}

Sparse Matrix Operator Kernel Emissions (SMOKE) model (Houyoux et al., 2000) and estimated using the U.S. EPA's 2002 National Emissions Inventory (NEI) (U.S. Environmental Protection Agency, 2004). Table S3 summarizes CMAQ domain and monthly total POA emissions in January and July 2002 for AE6 [where POA is the sum of primary organic carbon (POC) and primary noncarbon organic mass (PNCOM)], VBS, and high S/IVOC VBS (where SVOC emissions represent POA emissions). Because the CMAQ boundary conditions do not currently include gas- or particlephase VBS species, three $36-\mathrm{km}$ continental U.S. simulations, one each for AE6, VBS, and high S/IVOC VBS, were performed for January and July, 2002 and the results used to generate boundary

Table S2: Fraction of POA emissions allocated to SVOC volatility bins.

\begin{tabular}{cccccc}
\hline & & \multicolumn{4}{c}{$\mathrm{C}^{*}$} \\
& Non-Vol & $10^{0}$ & $10^{1}$ & $10^{2}$ & $10^{3}$ \\
\hline VBS & 0.09 & 0.09 & 0.14 & 0.18 & 0.5 \\
high S/IVOC VBS & 0.4 & 0.26 & 0.4 & 0.51 & 1.43 \\
\hline
\end{tabular}


conditions for the 12-km domain. For each nested 12-km simulation, the coarser domain used the identical OA scheme as the nested simulations.

Table S3: CMAQ emissions (tons) of primary organic carbon (POC), primary non-carbon organic mass (PNCOM), primary organic aerosol (POA, where POA = POC + PNCOM), SVOC, and IVOC for CMAQ with AE6, VBS, and high S/IVOC VBS (VBSh).

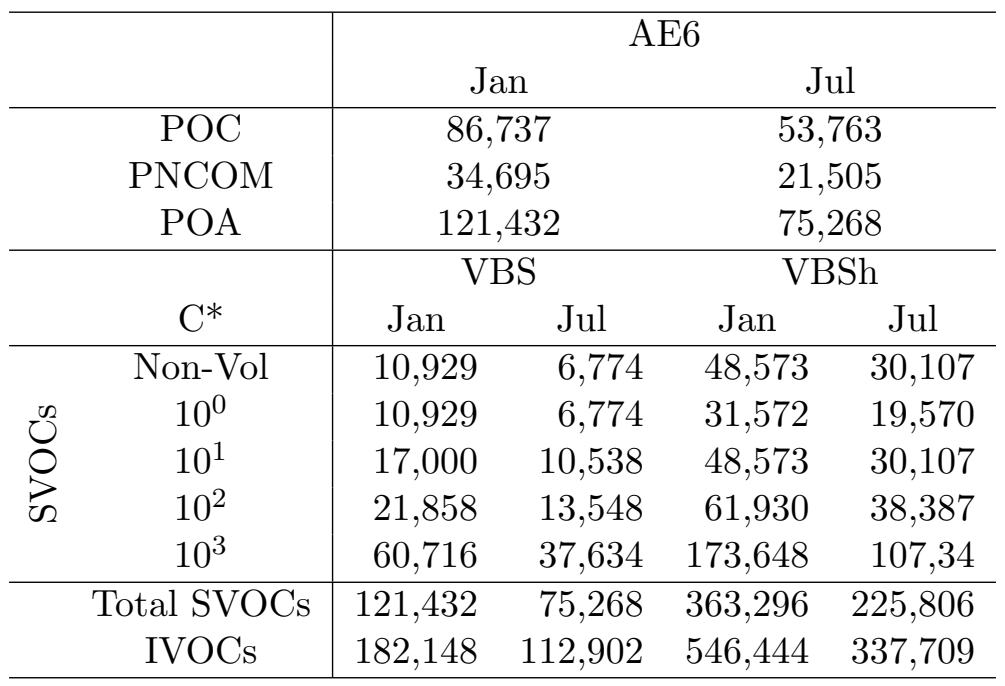

Model estimates of total fine particulate matter $\left(\mathrm{PM}_{2.5}\right)$ and organic carbon (OC) concentrations were compared against observations at Chemical Speciation Network (CSN) (http://www . epa.gov/ttn/amtic/speciepg.html) and Interagency Monitoring of Protected Visual Environments (IMPROVE) network sites (http://vista.cira.colostate.edu/improve) and OC observations at Southeastern Aerosol Research and Characterization (SEARCH) network sites (http: //www.atmospheric-research.com/studies/SEARCH). Additional information about the monitoring sites, such as the number of sites in the domain (Table S7), their locations (Figure S5), and performance at sites located closest to ATL (Tables S8 and S9) are provided in Section 2. Note that the VBS implementation in CMAQ does not track primary organic carbon and primary non-carbon organic matter separately as in AE6, only estimating primary organic aerosols. Therefore, primary OC was estimated assuming an OM/OC ratio of 1.4, similar to Lane et al. (2008); Murphy and Pandis (2009, 2010). PNCOM emission estimates were adjusted to account for this assumption and to maintain consistency between the model scenarios. For SOA, the EPA recommended precursor-specific OC/OM ratios, which range from 1.4 to 2.7, were used to calculate AE6 OC. VBS, however, does not track mass formed from each parent precursor separately as in AE6 and therefore an OC/OM ratio of 2 was assumed for all secondary species, similar to Murphy and Pandis $(2009,2010)$. 


\section{$1.3 \quad$ Results}

\subsubsection{Organic Carbon}

In both January and July 2002, VBS predicted lower OC concentrations compared to AE6, primarily due to the evaporation of POA from the particle phase to the gas phase (Figures S1b and e). This effect was more pronounced in winter (Figure S1b), when POA emissions were approximately 1.6 times higher than in summer (Figure S1e and Table S3). While differences in summer appear relatively small on an absolute change basis (Figure S1) compared to winter, low overall concentrations of OC in summer somewhat obscure the differences between AE6 and VBS, which are actually similar to those in winter on a percent change basis. Compared to AE6, high S/IVOC VBS predicted higher OC concentrations in the south and portions of the northeast in winter, and near the Great Lakes and in Colorado in summer (Figures S1c,f) largely due to anthropogenic SOA formed from oxidative aging of S/IVOCs from sources of POA emissions (e.g. wildfire in Colorado in July). Evaporation of POA, which impacted VBS OC results, was generally offset by the increased emissions of S/IVOCs.
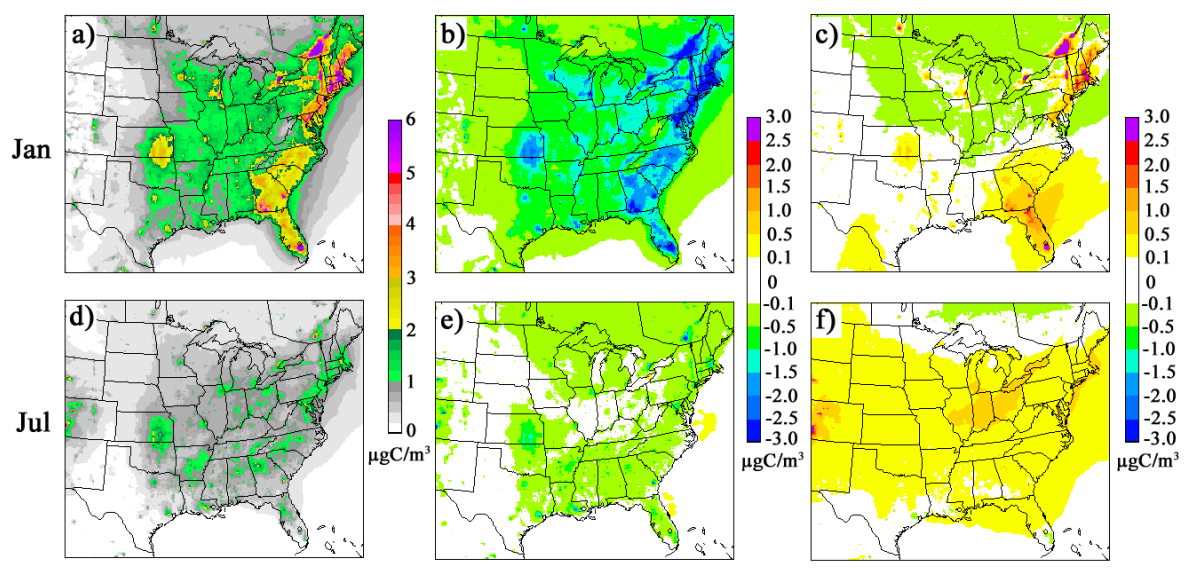

Figure S1: Monthly average OC concentrations for CMAQ with AE6 in a) January and d) July, CMAQ with VBS minus CMAQ with AE6 in b) January and e) July, and CMAQ with VBS and high S/IVOC emissions minus CMAQ with AE6 in c) January and f) July.

Comparing individual components of OC (anthropogenic SOA, biogenic SOA, and POA), VBS predicted higher concentrations of anthropogenic SOA than AE6, but lower concentrations of biogenic SOA (with the exception of slightly higher concentrations in the South during July) and POA (Figures S2a-c and e-g). Lower POA concentrations appear to have shifted gas-particle partitioning of SOA from the particle phase to the gas phase in VBS, effectively lowering SOA concentrations throughout the domain. Aging, changes in yields, and conversion of POA to anthropogenic SOA 
appear to have counteracted this effect to produce higher anthropogenic SOA concentrations, with aging and the conversion of POA likely more important in summer due to the additional photooxidation which occurs during warmer months. For biogenic SOA, differences in yields appear to have counteracted the shift in partitioning to produce higher concentrations in the South, where biogenic emissions are highest (despite lower overall organic mass available for particle partitioning), but not in other areas. Compared to VBS, the high S/IVOC VBS predictions were similar for biogenic SOA (slightly higher concentrations in the South during July likely due to additional organic mass shifting gas-particle partitioning to the particle phase), and a similar spatial pattern for anthropogenic SOA but with a larger magnitude. POA concentrations in the high S/IVOC case were higher than AE6 near POA emission sources due to the increase in S/IVOC emissions in winter but slightly lower in other areas due to partitioning to the gas phase (Figure S2d). In summer, POA concentrations were likely lowered by aging reactions, which shifted a portion of POA mass to anthropogenic SOA (Figure S2h).
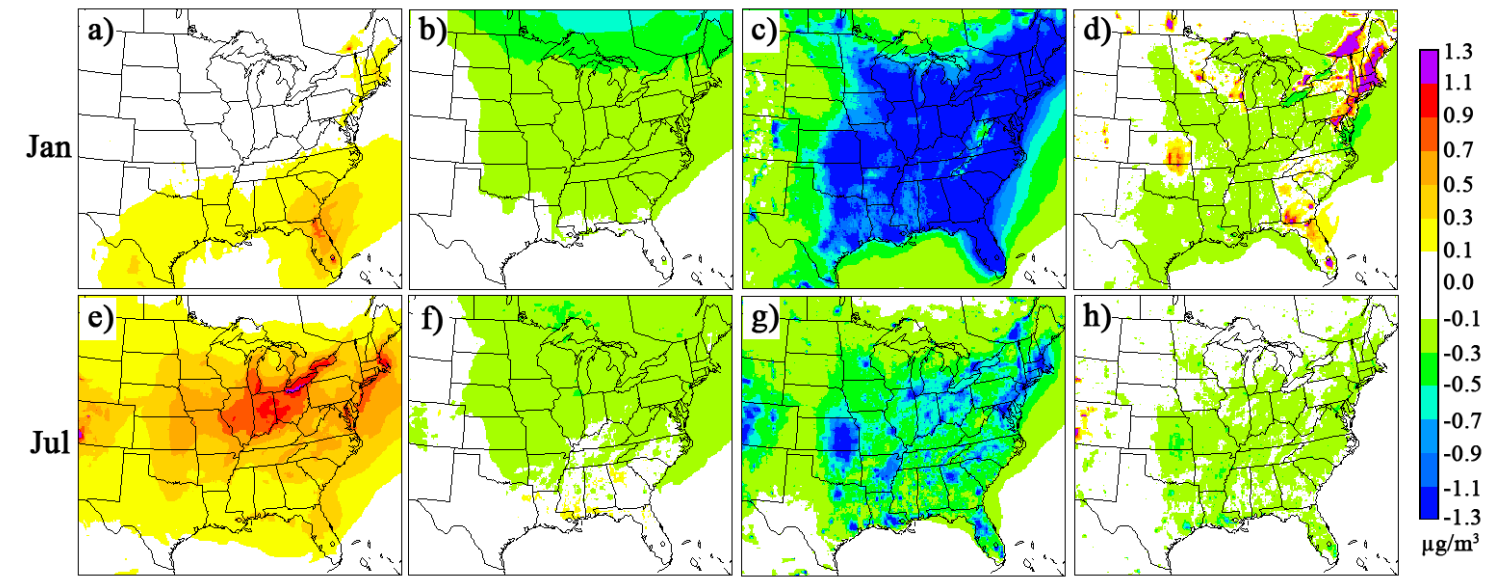

Figure S2: Monthly average absolute difference of CMAQ with VBS minus CMAQ with AE6 in January for a) anthropogenic SOA b) biogenic SOA c) and POA and in July for e) anthropogenic SOA f) biogenic SOA g) and POA. Monthly average absolute difference of CMAQ with VBS and high S/IVOC emissions minus CMAQ with AE6 for POA concentrations in d) January and h) July.

Figure S3 indicates the normalized mean bias (NME) and normalized mean error (NME) for all PM species, including OC, and Tables S6-S9 indicate the fractional error (FE) and fractional bias (FB), the recommended model performance metrics for PM (Boylan and Russell, 2006), for $\mathrm{OC}$ and $\mathrm{PM}_{2.5}$. OC model performance comparisons indicate that in general, the VBS treatment performed worse at CSN and IMPROVE monitor locations compared to AE6 (Figure S3, Tables S6 and S8). Lower concentrations in VBS led to more severe underpredictions of OC at CSN sites in January and July and at IMPROVE sites in January where AE6 also underpredicted OC. At IMPROVE sites in January, the underprediction of OC using VBS [FB of -106\%] was worse than 
using AE6 (FB of -5.9\%) (Table S6). At SEARCH sites, VBS generally performed better than AE6 in January where AE6 overpredicted OC. Lower OC concentrations in VBS slightly improved FB (150\%) compared to AE6 (166\%) while FE was slightly worse (from 174\% in AE6 to $185 \%$ in VBS). However, these values are considered rather poor model performance overall. Performance using VBS with high S/IVOCs estimates was, in general, similar to AE6. FBs were slightly higher at CSN and SEARCH sites using high S/IVOC VBS compared to AE6 (Table S6). In instances where AE6 underpredicted OC (CSN in July), high S/IVOC VBS improved FB whereas when AE6 overpredicted OC (SEARCH in January and July), high S/IVOC VBS tended to more severely overpredict OC. The poor model performance in VBS was largely attributable to the semi-volatile treatment of POA, as a portion of the POA emissions were partitioned into the gas phase. This effect was somewhat counteracted by the higher POA emissions in the high S/IVOC emission case.

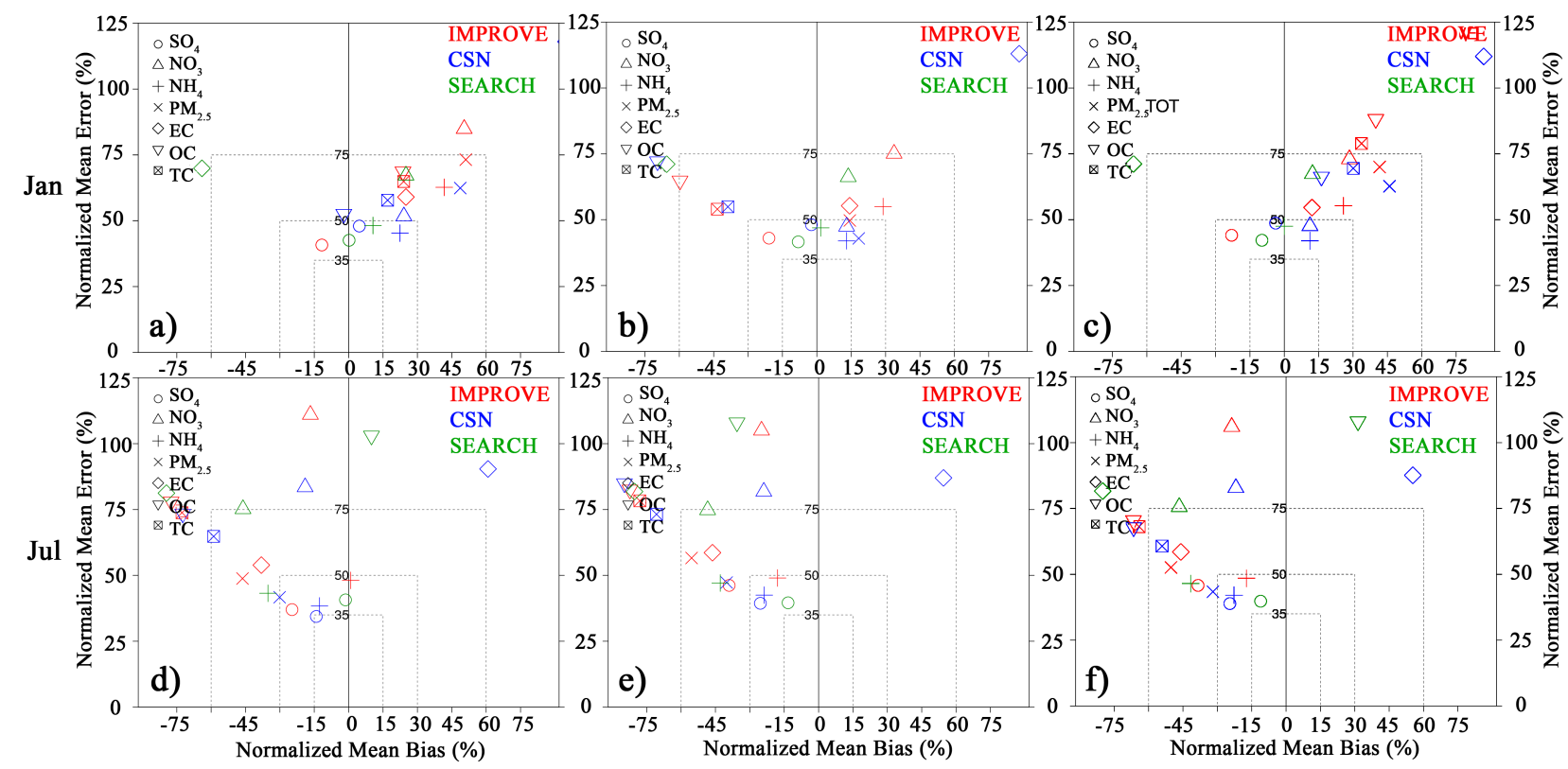

Figure S3: Normalized mean bias and normalized mean error at CSN, IMPROVE, and SEARCH monitor sites in January for a) CMAQ, b) CMAQ with VBS, and c) CMAQ with VBS and high S/IVOCs and in July for d) CMAQ, e) CMAQ with VBS, and f) CMAQ with VBS and high $\mathrm{S} /$ IVOCs. PM species include sulfate $\left(\mathrm{SO}_{4}\right)$, nitrate $\left(\mathrm{NO}_{3}\right)$, ammonium $\left(\mathrm{NH}_{4}\right), \mathrm{PM}_{2.5}$, elemental carbon (EC), organic carbon (OC), and total carbon (TC).

To test the sensitivity of POA aging on OC concentrations in VBS, an alternative aging scheme proposed by Pye and Seinfeld (2010) was implemented over the same modeling domain and time periods. The Pye and Seinfeld (2010) aging scheme uses a rate constant of $2 \times 10^{-11} \mathrm{~cm}^{3}$ molecules $^{-1}$ $\mathrm{s}^{-1}$ (vs. $4 \times 10^{-11} \mathrm{~cm}^{3}$ molecules ${ }^{-1} \mathrm{~s}^{-1}$ ), lowers volatility by two orders of magnitude (vs. one order of magnitude), only allows for one oxidation step per parent hydrocarbon (vs. multi-generational aging), and assumes that oxidation produces a product $50 \%$ heavier than the parent hydrocarbon 
(vs. no increase). Model predictions of OC using the alternative aging scheme were nearly identical during the summer at $\mathrm{CSN}\left(0.454 \mathrm{\mu gC} \mathrm{m}^{-3}\right.$ in the alternative aging scheme vs. $0.452 \mu \mathrm{gC} \mathrm{m}^{-3}$ in the CMAQ aging scheme) and IMPROVE (0.747 vs. $0.743 \mu \mathrm{gC} \mathrm{m}^{-3}$ ) monitoring locations and marginally higher in winter (0.479 vs. $0.441 \mu \mathrm{gC} \mathrm{m} \mathrm{m}^{-3}$ at CSN sites and 0.936 vs. $0.884 \mu \mathrm{gC} \mathrm{m}^{-3}$ at IMPROVE sites). The slight increase in OC concentrations did little to improve model performance given the underpredictions of $\mathrm{OC}\left(0.7\right.$ to $\left.4.2 \mathrm{\mu gC} \mathrm{m}^{-3}\right)$ with VBS.

Koo et al. (2014) reported similar OC model performance at CSN and IMPROVE monitoring locations in the Eastern U.S. using CMAQ v5.0.1 with CB05 and VBS; VBS model performance was markedly worse in winter and marginally worse in summer compared to AE6. In the high S/IVOC, Koo et al. (2014) indicated similar results in winter (performance similar to AE6) but with significant improvements to performance in summer. In a separate study, Koo et al. (2013) showed that the high S/IVOC case in CMAQ generally improved performance in February and August, 2005. The traditional aerosol treatment in CMAQ [AE5 in Koo et al. (2013)] generally underpredicted OC and therefore the higher predictions of the high S/IVOC case improved performance [note that Koo et al. (2013) did not report results for CMAQ with VBS and conservative estimates of S/IVOC emissions).

Koo et al. (2014) also reported results for an implementation of VBS in the Comprehensive Air Quality Model with Extensions (CAMx) (ENVIRON, 2013). In CAMx, model performance between the traditional OA modeling scheme, VBS, and high S/IVOC VBS were mixed depending on the time of year and network. In the Weather Research and Forecasting model coupled with Chemistry (WRF-Chem) (Grell et al., 2005), Li et al. (2011) reported that VBS with high estimates of S/IVOC emissions generally improved model performance in Mexico City, where the traditional 2-product OA treatment previously underpredicted OA. Given the mixed model performance in CMAQ (as well as CAMx), future efforts are needed to refine the VBS treatment, particularly the $\mathrm{S} / \mathrm{IVOC}$ emission inputs, to improve CMAQ model performance. With the variation in seasonal performance, one possible improvement would be to use seasonally specific S/IVOC emission estimates as proposed by Koo et al. (2014). Another improvement would be to use source-specific S/IVOC emission inputs. The CMAQ v5.0.2 implementation of VBS provides the flexibility to estimate S/IVOC emissions using different scaling factors applied to gas vehicle POA emissions, diesel vehicle POA emissions, and all other anthropogenic POA emissions. However, the default approach used in this study applies the same S/IVOC scaling factor to POA emissions from all sources, as source specific scaling factors for CMAQ were not available at the time this study was performed. 


\subsection{2 $\quad \mathbf{P M}_{2.5}$}

VBS lowered total $\mathrm{PM}_{2.5}$ concentrations throughout the Eastern U.S. in both January and July (Figures S4b,e). The same was true for the high S/IVOC case with the exception of Florida and portions of the Northeast in January and Colorado in the summer (Figures S4c,f). The reduction of $\mathrm{PM}_{2.5}$ concentrations with VBS led to mixed impacts on model performance (Figure S3). Instances where CMAQ previously overpredicted total PM (CSN and IMPROVE in January) (Table S7), VBS improved performance though due to compensating bias. Alternatively, in cases where CMAQ previously underpredicted total PM (CSN and IMPROVE in July) (Table S7), VBS worsened model performance.
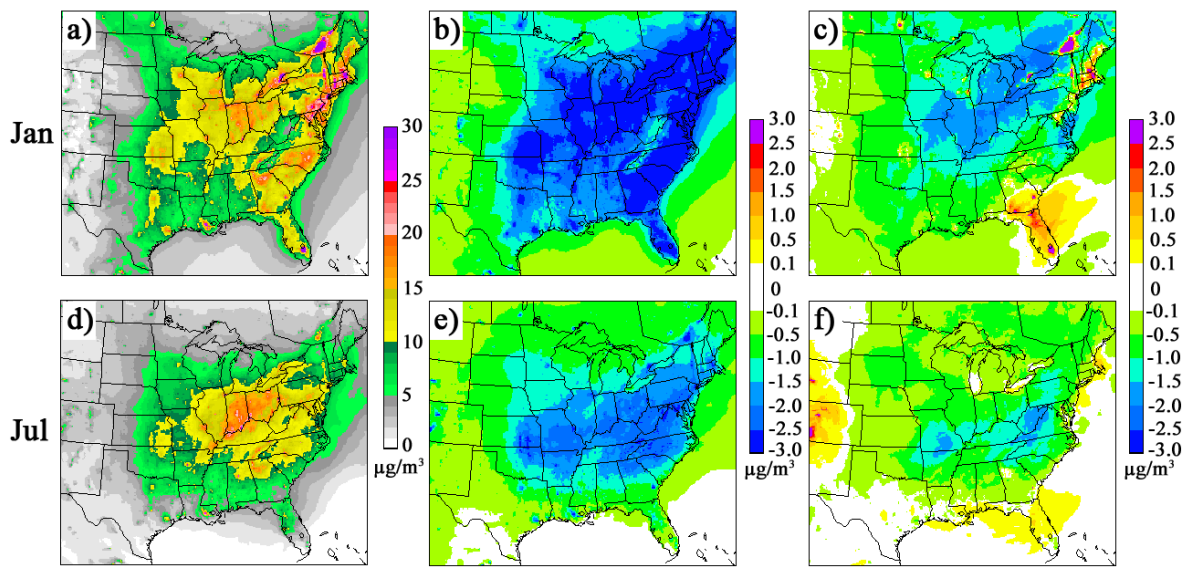

Figure S4: Monthly average $\mathrm{PM}_{2.5}$ concentrations for CMAQ with AE6 in a) January and d) July. Monthly average absolute difference in CMAQ with AE6 minus CMAQ with VBS in b) January and e) July and CMAQ with AE6 minus CMAQ with VBS and high S/IVOC emissions in c) January and f) July.

Comparing total $\mathrm{PM}_{2.5}$ concentrations between organic aerosol schemes, it is worth noting that the total change in $\mathrm{PM}_{2.5}$ concentrations was not completely attributable to changes in organics. For example, reductions in summertime $\mathrm{PM}_{2.5}$ concentrations in the VBS case (or summer and winter concentrations in the high S/IVOC case) did not agree spatially with changes in OC concentrations (Figures S1c,e,f and S4e,c,f). Comparisons of mean concentrations also support this finding, e.g. mean $\mathrm{OC}$ concentrations in January of $2.8 \mu \mathrm{gC} \mathrm{m} \mathrm{m}^{-3}$ and $0.9 \mu \mathrm{gC} \mathrm{m}{ }^{-3}$ for AE6 and VBS respectively (difference of $1.9 \mu \mathrm{gC} \mathrm{m}{ }^{-3}$ ) vs. total $\mathrm{PM}_{2.5}$ concentrations of $18.4 \mu \mathrm{g} \mathrm{m}^{-3}$ and $14.7 \mu \mathrm{g} \mathrm{m}^{-3}$ (difference of $3.7 \mathrm{\mu g} \mathrm{m}^{-3}$ ). The additional differences were due to an increase in dry deposition of $\mathrm{PM}_{2.5}$ species, which reduced non-organic PM concentrations in VBS by 9-17.5\%. 


\section{Additional Figures and Tables}

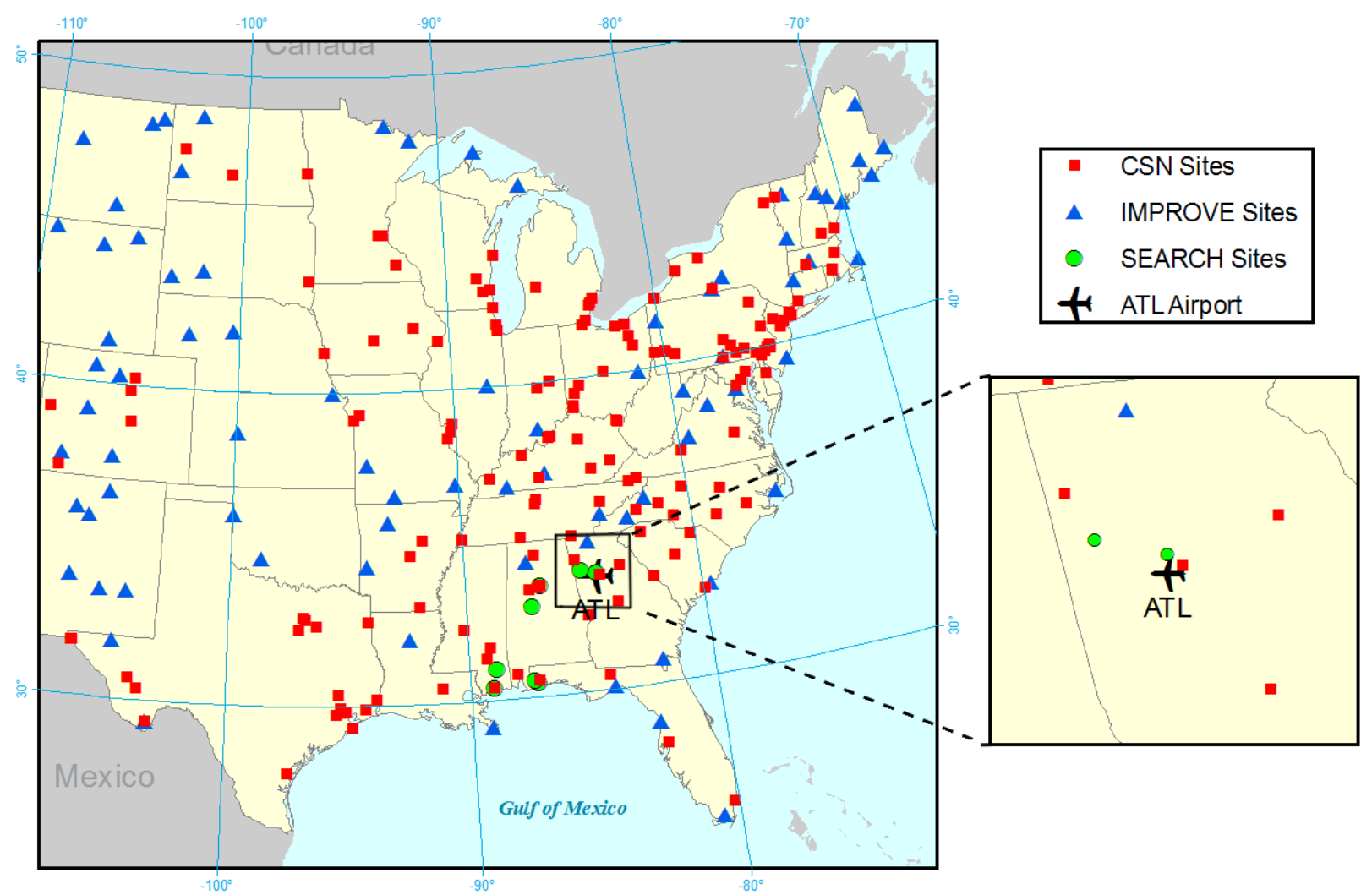

Figure S5: Locations of CSN, IMPROVE, and SEARCH ambient monitors in domain as well as the Atlanta Airport. In the zoomed portion of the map, the SEARCH site (green circle) located near ATL is the Jefferson Street site and the CSN site (red square) is the Decatur site. 
Table S4: Updates to existing CMAQ SAPRC-07 reactions for VBS based on Koo et al. (2014). Where RXN products are replaced by $\mathrm{RO} 2$, high and low $\mathrm{NO}_{x}$ yields replace $\mathrm{NO}_{x}$ independent yields. SV_BVB and SV_AVB correspond to semi-volatile biogenic and anthropogenic SOA species, respectively. Newly added reactions (those without a corresponding reaction in SAPRC-07 without VBS) are listed in Table S5.

\begin{tabular}{|c|c|c|}
\hline Reactants & Default Product & Updated VBS CMAQ Product(s) \\
\hline ISOPRENE + OH & ISOPRXN & ISOPRO2 \\
\hline $\mathrm{APIN}+\mathrm{OH}$ & TRPRXN & TRPRO2 \\
\hline $\mathrm{APIN}+\mathrm{O} 3$ & TRPRXN & TRPRO2 \\
\hline $\mathrm{APIN}+\mathrm{NO} 3$ & TRPRXN & TRPRO2 \\
\hline $\mathrm{TERP}+\mathrm{OH}$ & TRPRXN & TRPRO2 \\
\hline $\mathrm{TERP}+\mathrm{O} 3$ & TRPRXN & TRPRO2 \\
\hline $\mathrm{TERP}+\mathrm{NO} 3$ & TRPRXN & TRPRO2 \\
\hline $\mathrm{ALK} 5+\mathrm{OH}$ & ALK5RXN & ALK5RO2 \\
\hline $\mathrm{SESQ}+\mathrm{OH}$ & SESQRXN & $\begin{array}{l}0.092 * \mathrm{SV} \_\mathrm{BVB} 1+0.188^{*} \mathrm{SV} \_\mathrm{BVB} 2+ \\
0.968^{*} \mathrm{SV} \_\mathrm{BVB} 3+0.679 * \mathrm{SV} \_\mathrm{BVB} 4\end{array}$ \\
\hline $\mathrm{SESQ}+\mathrm{O} 3$ & SESQRXN & $\begin{array}{l}0.092 * \mathrm{SV} \_B V B 1+0.188 * \mathrm{SV} \_\mathrm{BVB} 2+ \\
0.968 * \mathrm{SV} \_\mathrm{BVB} 3+0.679 * \mathrm{SV} \_\mathrm{BVB} 4\end{array}$ \\
\hline $\mathrm{SESQ}+\mathrm{NO} 3$ & SESQRXN & $\begin{array}{l}0.092 * \mathrm{SV} \_B V B 1+0.188 * \mathrm{SV} \_\mathrm{BVB} 2+ \\
0.968 * \mathrm{SV} \text { _BVB3 }+0.679 * \mathrm{SV} \text { BVVB4 }\end{array}$ \\
\hline $\mathrm{SESQ}+\mathrm{O} 3 \mathrm{P}$ & SESQRXN & $\begin{array}{l}0.092 * \mathrm{SV} \_\mathrm{BVB} 1+0.188^{*} \mathrm{SV} \_\mathrm{BVB} 2+ \\
0.968^{*} \mathrm{SV} \_\mathrm{BVB} 3+0.679 * \mathrm{SV} \_\mathrm{BVB} 4\end{array}$ \\
\hline BENZRO2 + NO & BNZNRXN & $\begin{array}{l}0.001 * \mathrm{SV} \_\mathrm{AVB} 1+0.079 * \mathrm{SV} \_\mathrm{AVB} 2+ \\
0.148 * \mathrm{SV} \_\mathrm{AVB} 3+0.222 * \mathrm{SV} \_\mathrm{AVB} 4\end{array}$ \\
\hline BENZRO2 + HO2 & BNZHRXN & $\begin{array}{l}0.035 * \mathrm{SV} \_\mathrm{AVB} 1+0.108^{*} \mathrm{SV} \_\mathrm{AVB} 2+ \\
0.185 * \mathrm{SV} \_\mathrm{AVB} 3+0.268^{*} \mathrm{SV} \_\mathrm{AVB} 4\end{array}$ \\
\hline $\mathrm{XYLRO} 2+\mathrm{NO}$ & XYLNRXN & $\begin{array}{l}0.001 * \mathrm{SV} \_\mathrm{AVB} 1+0.127^{*} \mathrm{SV} \_\mathrm{AVB} 2+ \\
0.201 * \mathrm{SV} \_\mathrm{AVB} 3+0.301 * \mathrm{SV} \_\mathrm{AVB} 4\end{array}$ \\
\hline $\mathrm{XYLRO} 2+\mathrm{HO} 2$ & XYLHRXN & $\begin{array}{l}0.048^{*} \mathrm{SV} \_\mathrm{AVB} 1+0.195 * \mathrm{SV} \_\mathrm{AVB} 2+ \\
0.252 * \mathrm{SV} \text { _AVB3 }+0.364 * \mathrm{SV} \_\mathrm{AVB} 4\end{array}$ \\
\hline TOLRO2 + NO & TOLNRXN & $\begin{array}{l}0.006 * \mathrm{SV} \_\mathrm{AVB} 1+0.145^{*} \mathrm{SV} \_\mathrm{AVB} 2+ \\
0.281 * \mathrm{SV} \_\mathrm{AVB} 3+0.432 * \mathrm{SV} \_\mathrm{AVB} 4\end{array}$ \\
\hline TOLRO2 + HO2 & TOLHRXN & $\begin{array}{l}0.006 * \mathrm{SV} \_\mathrm{AVB} 1+0.145^{*} \mathrm{SV} \_\mathrm{AVB} 2+ \\
0.437^{*} \mathrm{SV} \_\mathrm{AVB} 3+0.281 * \mathrm{SV} \_\mathrm{AVB} 4\end{array}$ \\
\hline
\end{tabular}


Table S5: Newly added reactions for SAPRC-07 for CMAQ with VBS based on Koo et al. (2014). SV_BVB, SV_AVB, SV_PVB, and SV_FVB correspond to semi-volatile biogenic SOA, anthropogenic SOA, anthropogenic POA, and biogenic POA (biomass burning), respectively and similarly IVOC_P and IVOC_F correspond to anthropogenic and biogenic IVOCs.

\begin{tabular}{|c|c|}
\hline Reactants & Product(s) \\
\hline ISOPRENE + O3 & ISOPRO2 \\
\hline ISOPRENE + NO3 & ISOPRO2 \\
\hline ISOPRO $2+\mathrm{NO}$ & $\begin{array}{l}0.000 * \mathrm{SV} \_B V B 1+0.009 * \mathrm{SV} \_B V B 2+ \\
0.006 * \mathrm{SV} \text { SBVB } 3+0.000 * \mathrm{SV} \_\mathrm{BVB} 4\end{array}$ \\
\hline ISOPRO2 + HO2 & $\begin{array}{l}0.004 * \text { SV_BVB } 1+0.013 * \text { SV_BVB } 2+ \\
0.006 * \text { SV_BVB } 3+0.000 * \text { SV_BVB } 4\end{array}$ \\
\hline TRPRO2 + NO & $\begin{array}{l}0.010 * \text { SV_BVB } 1+0.101 * \text { SV_BVB } 2+ \\
0.173 * \text { SV_BVB } 3+0.451 * \text { SV_BVB } 4\end{array}$ \\
\hline TRPRO2 + HO2 & $\begin{array}{l}0.087 * \mathrm{SV} \_B V B 1+0.077 * \mathrm{SV} \_\mathrm{BVB} 2+ \\
0.309 * \mathrm{SV} \text { BVVB } 3+0.540 * \mathrm{SV} \_\mathrm{BVB} 4\end{array}$ \\
\hline $\mathrm{ALK} 5 \mathrm{RO} 2+\mathrm{NO}$ & $\begin{array}{l}0.000 * \mathrm{SV} \_A V B 1+0.109 * \mathrm{SV} \_A V B 2+ \\
0.000 * \mathrm{SV} \_A V B 3+0.000 * \mathrm{SV} \_A V B 4\end{array}$ \\
\hline ALK5RO2 + $\mathrm{HO} 2$ & $\begin{array}{l}0.000 * \text { SV_AVB } 1+0.219 * \text { SV_AVB } 2+ \\
0.000 * \text { SV_AVB } 3+0.000 * \text { SV_AVB } 4\end{array}$ \\
\hline $\mathrm{SV} \_\mathrm{AVB} 1+\mathrm{OH}$ & SV_AVB0 \\
\hline $\mathrm{SV} \_\mathrm{AVB} 2+\mathrm{OH}$ & SV_AVB1 \\
\hline $\mathrm{SV} \_\mathrm{AVB} 3+\mathrm{OH}$ & SV_AVB2 \\
\hline $\mathrm{SV} \_\mathrm{AVB} 4+\mathrm{OH}$ & SV_AVB3 \\
\hline SV_PVB1 $+\mathrm{OH}$ & $0.864 * \mathrm{SV} \_\mathrm{PVB} 0+0.142 * \mathrm{SV} \_\mathrm{AVB} 0$ \\
\hline $\mathrm{SV} \_\mathrm{PVB} 2+\mathrm{OH}$ & $0.877 *$ SV_PVB1 $+0.129 *$ SV_AVB1 \\
\hline $\mathrm{SV} \_\mathrm{PVB} 3+\mathrm{OH}$ & $0.889 *$ SV_PVB2 + 0.116*SV_AVB2 \\
\hline $\mathrm{SV} \_\mathrm{PVB} 4+\mathrm{OH}$ & $0.869 *$ SV_PVB3 + 0.137*SV_AVB3 \\
\hline $\mathrm{SV} \_\mathrm{FVB} 1+\mathrm{OH}$ & $0.538 * \mathrm{SV} \_\mathrm{FVB} 0+0.464 * \mathrm{SV} \_\mathrm{BVB} 0$ \\
\hline $\mathrm{SV} \_\mathrm{FVB} 2+\mathrm{OH}$ & $0.689 * \mathrm{SV}$ FVB1 $+0.313 * \mathrm{SV}$ _BVB1 \\
\hline $\mathrm{SV} \_\mathrm{FVB} 3+\mathrm{OH}$ & $0.783 *$ SV_FVB2 $+0.220 *$ SV_BVB2 \\
\hline $\mathrm{SV} \_\mathrm{FVB} 4+\mathrm{OH}$ & $0.846^{*}$ SV_FVB3 + 0.156*SV_BVB3 \\
\hline IVOC_P + OH & $\begin{array}{c}0.033^{*} \mathrm{SV} \_\mathrm{AVB} 1+0.216^{*} \mathrm{SV} \_\mathrm{AVB} 2+ \\
0.304^{*} \mathrm{SV} \_\mathrm{AVB} 3+0.447^{*} \mathrm{SV} \_\mathrm{AVB} 4\end{array}$ \\
\hline IVOC_F + OH & $\begin{array}{c}0.033^{*} \text { SV_BVB } 1+0.216 * \text { SV_BVB2 }+ \\
0.304 * \text { SV_BVB } 3+0.447^{*} \text { SV_BVB } 4\end{array}$ \\
\hline
\end{tabular}


Table S6: Mean organic carbon concentrations, fractional bias (FB) and fractional error (FE) for CMAQ (AE6), CMAQ with VBS (VBS), and CMAQ with VBS and high S/IVOC emissions (VBSh) for CSN, IMPROVE, and SEARCH monitor sites located within the model domain.

\begin{tabular}{cccccc|ccc|ccc}
\hline $\begin{array}{c}\text { Network } \\
\text { (\# of sites) }\end{array}$ & & \multicolumn{4}{c|}{ Mean Conc. $\left(\mu \mathrm{g} \mathrm{m} \mathrm{m}^{-3}\right)$} & \multicolumn{3}{c|}{ FB $(\%)$} & \multicolumn{3}{c}{ FE $(\%)$} \\
\hline CSN & Jan & 2.9 & 2.8 & 0.9 & 3.4 & -3.3 & -105 & 0.4 & 53.0 & 111 & 58.4 \\
$(173)$ & Jul & 4.9 & 1.3 & 0.7 & 1.6 & -103 & -140 & -92.3 & 107 & 142 & 95.8 \\
IMPROVE & Jan & 1.1 & 1.4 & 0.4 & 1.5 & -5.9 & -106 & -14.6 & 59.6 & 109 & 67.8 \\
$(83)$ & Jul & 2.6 & 0.6 & 0.5 & 0.9 & -118 & -132 & -93.7 & 119 & 132 & 97.4 \\
SEARCH & Jan & 0.7 & 2.0 & 0.7 & 2.3 & 166 & 150 & 168 & 174 & 185 & 173 \\
$(8)$ & Jul & 1.2 & 1.3 & 0.8 & 1.6 & 121 & 105 & 124 & 158 & 174 & 155 \\
\hline
\end{tabular}

Table S7: Mean $\mathrm{PM}_{2.5}$ concentrations, fractional bias (FB) and fractional error (FE) for CMAQ (AE6), CMAQ with VBS (VBS), and CMAQ with VBS and high S/IVOC emissions (VBSh) for CSN, IMPROVE, and SEARCH monitor sites located within the model domain.

\begin{tabular}{cccccc|ccc|ccc}
\hline \multirow{2}{*}{$\begin{array}{c}\text { Network } \\
\text { (\# of sites) }\end{array}$} & & Obs. & AE6 & VBS & VBSh & AE6 & VBS & VBSh & AE6 & VBS & VBSh \\
\hline CSN & Jan & 12.4 & 18.4 & 14.7 & 18.1 & 27.8 & 5.5 & 23.0 & 47.0 & 39.4 & 46.8 \\
$(173)$ & Jul & 18.4 & 12.9 & 11.0 & 12.5 & -39.9 & -53.3 & -44.6 & 53.1 & 62.2 & 57.5 \\
IMPROVE & Jan & 5.4 & 8.2 & 6.2 & 7.7 & 24.6 & 0.5 & 14.4 & 53.8 & 47.9 & 53.1 \\
$(83)$ & Jul & 12.5 & 6.7 & 5.6 & 6.2 & -69.1 & -82.8 & -81.4 & 72.7 & 85.0 & 84.3 \\
\hline
\end{tabular}

Table S8: Mean organic concentrations, fractional bias (FB) and fractional error (FE) for CMAQ (AE6), CMAQ with VBS (VBS), and CMAQ with VBS and high S/IVOC emissions (VBSh) for the CSN monitor (Site No. 130890002, located approximately $15 \mathrm{~km}$ northeast of the airport in Decatur, GA) and SEARCH monitor [Jefferson Street Site (JST), located approximately $15 \mathrm{~km}$ north of the airport in downtown Atlanta, GA] closest to the Atlanta Airport.

\begin{tabular}{cccccc|ccc|ccc}
\hline \multirow{2}{*}{ Network } & & \multicolumn{4}{c|}{ Mean Conc. $\left(\mu \mathrm{g} \mathrm{m}^{-3}\right)$} & \multicolumn{3}{c|}{ FB $(\%)$} & \multicolumn{3}{c}{ FE $(\%)$} \\
& & Obs. & AE6 & VBS & VBSh & AE6 & VBS & VBSh & AE6 & VBS & VBSh \\
\hline \multirow{2}{*}{ Decatur } & Jan & 4.6 & 3.1 & 1.0 & 3.5 & -29.5 & -127 & -21.2 & 34.1 & 127 & 25.4 \\
& Jul & 4.6 & 1.2 & 0.8 & 1.5 & -112 & 105 & -99.4 & 112 & 195 & 99.4 \\
\multirow{2}{*}{ JST } & Jan & 4.5 & 3.5 & 1.1 & 4.1 & -18.0 & -115 & -5.2 & 34.0 & 118 & 27.6 \\
& Jul & 4.0 & 2.1 & 1.1 & 2.5 & -53.1 & -105 & -43.5 & 66.4 & 118 & 57.3 \\
\hline
\end{tabular}


Table S9: Mean $\mathrm{PM}_{2.5}$ concentrations, fractional bias (FB) and fractional error (FE) for CMAQ (AE6), CMAQ with VBS (VBS), and CMAQ with VBS and high S/IVOC emissions (VBSh) for the CSN monitor (Site No. 130890002, located approximately $15 \mathrm{~km}$ northeast of the airport in Decatur, GA) closest to the Atlanta Airport.

\begin{tabular}{|c|c|c|c|c|c|c|c|c|c|c|c|}
\hline \multirow{2}{*}{\multicolumn{2}{|c|}{ Network }} & \multicolumn{4}{|c|}{ Mean Conc. $\left(\mu \mathrm{g} \mathrm{m}^{-3}\right)$} & \multicolumn{3}{|c|}{$\mathrm{FB}(\%)$} & \multicolumn{3}{|c|}{$\mathrm{FE}(\%)$} \\
\hline & & Obs. & AE6 & VBS & VBSh & AE6 & VBS & VBSh & AE6 & VBS & VBSh \\
\hline & & 13.7 & 194 & 15.6 & 19.2 & 35.2 & 12.2 & 32.8 & 36.0 & 23.4 & 36.6 \\
\hline & Jul & 18.2 & 11.9 & 10.5 & 12.0 & -56.2 & -69.9 & -52.0 & 56.2 & 69.9 & 53.9 \\
\hline
\end{tabular}




\section{References}

Boylan, J. W. and Russell, A. G.: PM and light extinction model performance metrics, goals, and criteria for three-dimensional air quality models, Atmospheric Environment, 40, 4946-4959, 2006.

Carter, W. P.: Development of the SAPRC-07 chemical mechanism, Atmospheric Environment, 44, 5324-5335, 2010.

Donahue, N. M., Henry, K. M., Mentel, T. F., Kiendler-Scharr, A., Spindler, C., Bohn, B., Brauers, T., Dorn, H. P., Fuchs, H., Tillmann, R., et al.: Aging of biogenic secondary organic aerosol via gas-phase OH radical reactions, Proceedings of the National Academy of Sciences, 109, 13 503$13508,2012$.

ENVIRON: User's Guide to the Comprehensive Air Quality Model with Extensions (CAMx) Version 6.0, ENVIRON International Corporation, Novato, CA, URL http://www.camx.com/files/ camxusersguide_v6-00.pdf, 2013.

Grell, G. A., Dudhia, J., and Stauffer, D. R.: A description of the fifth-generation Penn State/NCAR mesoscale model (MM5), Tech. rep., Mesoscale and Microscale Meteorology Division, National Center for Atmospheric Research, 1994.

Grell, G. A., Peckham, S. E., Schmitz, R., McKeen, S. A., Frost, G., Skamarock, W. C., and Eder, B.: Fully coupled "online" chemistry within the WRF model, Atmospheric Environment, 39, 6957-6975, 2005.

Hildebrandt, L., Donahue, N., and Pandis, S.: High formation of secondary organic aerosol from the photo-oxidation of toluene, Atmospheric Chemistry and Physics, 9, 2973-2986, 2009.

Houyoux, M. R., Vukovich, J. M., Coats, C. J., Wheeler, N. J., and Kasibhatla, P. S.: Emission inventory development and processing for the Seasonal Model for Regional Air Quality (SMRAQ) project, Journal of Geophysical Research: Atmospheres, 105, 9079-9090, 2000.

Hutzell, W., Luecken, D., Appel, K., and Carter, W.: Interpreting predictions from the SAPRC07 mechanism based on regional and continental simulations, Atmospheric Environment, 46, 417429, 2012.

Koo, B., Knipping, E., and Yarwood, G.: An Improved Volatility Basis Set for Modeling Organic Aerosol in both CAMx and CMAQ, in: 33rd International Technical Meeting on Air Pollution Modelling and its Application, 2013.

Koo, B., Knipping, E., and Yarwood, G.: 1.5-Dimensional Volatility Basis Set Approach for Modeling Organic Aerosol in CAMx and CMAQ, Atmospheric Environment, 95, 158-164, 2014. 
Lane, T. E., Donahue, N. M., and Pandis, S. N.: Simulating secondary organic aerosol formation using the volatility basis-set approach in a chemical transport model, Atmospheric Environment, 42, 7439-7451, 2008.

Li, G., Zavala, M., Lei, W., Tsimpidi, A., Karydis, V., Pandis, S., Canagaratna, M., and Molina, L.: Simulations of organic aerosol concentrations in Mexico City using the WRF-CHEM model during the MCMA-2006/MILAGRO campaign, Atmospheric Chemistry and Physics, 11, 3789$3809,2011$.

Murphy, B. N. and Pandis, S. N.: Simulating the formation of semivolatile primary and secondary organic aerosol in a regional chemical transport model, Environmental Science \& Technology, 43, 4722-4728, 2009.

Murphy, B. N. and Pandis, S. N.: Exploring summertime organic aerosol formation in the eastern United States using a regional-scale budget approach and ambient measurements, Journal of Geophysical Research: Atmospheres, 115, 2010.

Odum, J. R., Hoffmann, T., Bowman, F., Collins, D., Flagan, R. C., and Seinfeld, J. H.: Gas/particle partitioning and secondary organic aerosol yields, Environmental Science \& Technology, 30, 2580$2585,1996$.

Pye, H. O. and Seinfeld, J. H.: A global perspective on aerosol from low-volatility organic compounds, Atmospheric Chemistry and Physics, 10, 4377-4401, 2010.

Robinson, A. L., Donahue, N. M., Shrivastava, M. K., Weitkamp, E. A., Sage, A. M., Grieshop, A. P., Lane, T. E., Pierce, J. R., and Pandis, S. N.: Rethinking organic aerosols: Semivolatile emissions and photochemical aging, Science, 315, 1259-1262, 2007.

Shrivastava, M., Fast, J., Easter, R., Gustafson Jr, W., Zaveri, R. A., Jimenez, J. L., Saide, P., and Hodzic, A.: Modeling organic aerosols in a megacity: comparison of simple and complex representations of the volatility basis set approach, Atmospheric Chemistry and Physics, 11, 6639-6662, 2011.

U.S. Environmental Protection Agency: 2002 National Emission Inventory, URL http: //www . epa . gov/ttn/chief/net/2002inventory.html, 2004.

Yarwood, G., Rao, S., Yocke, M., and Whitten, G. Z.: Updates to the Carbon Bond chemical mechanism: CB05, ENVIRON International Corporation, Novato, CA, URL http://www. camx . com/publ/pdfs/cb05_final_report_120805.pdf, 2005. 